\title{
Human Reliability
} Analysis for Computerized Procedures, Part Two: Applicability of Current Methods

\section{Annual Meeting of the Human Factors and Ergonomics Society}

\author{
Ronald L. Boring \\ David I. Gertman
}

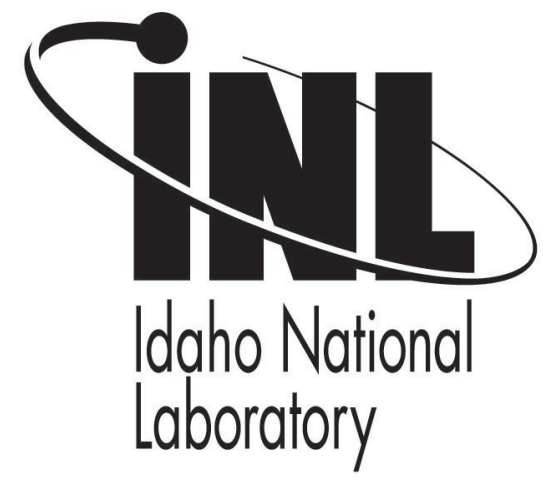

\section{October 2012}

This is a preprint of a paper intended for publication in a journal or proceedings. Since changes may be made before publication, this preprint should not be cited or reproduced without permission of the author. This document was prepared as an account of work sponsored by an agency of the United States Government. Neither the United States Government nor any agency thereof, or any of their employees, makes any warranty, expressed or implied, or assumes any legal liability or responsibility for any third party's use, or the results of such use, of any information, apparatus, product or process disclosed in this report, or represents that its use by such third party would not infringe privately owned rights. The views expressed in this paper are not necessarily those of the United States Government or the sponsoring agency. 


\title{
HUMAN RELIABILITY ANALYSIS FOR COMPUTERIZED PROCEDURES, PART TWO: APPLICABILITY OF CURRENT METHODS
}

\author{
Ronald L. Boring and David I. Gertman \\ Idaho National Laboratory, Idaho Falls, ID 83415, USA
}

\begin{abstract}
Computerized procedures (CPs) are an emerging technology within nuclear power plant control rooms. While CPs have been implemented internationally in advanced control rooms, to date no U.S. nuclear power plant has implemented CPs in its main control room. Yet, CPs are a reality of new plant builds and are an area of considerable interest to existing plants, which see advantages in terms of easier records management by omitting the need for updating hardcopy procedures. The overall intent of this paper is to provide a characterization of human reliability analysis (HRA) issues for computerized procedures. It is beyond the scope of this document to propose a new HRA approach or to recommend specific methods or refinements to those methods. Rather, this paper serves as a review of current HRA as it may be used for the analysis and review of computerized procedures.
\end{abstract}

\section{INTRODUCTION}

Computerized procedures (CPs) introduce new technology to the control room. The change in technology from paperbased to computerized procedures is analogous to other control room modernization efforts in which analog systems are replaced by digital systems. The Institute of Electrical and Electronics Engineers (IEEE) Standard 1786 (2011) and the Electric Power Research Institute (EPRI) 1015313 standard (2010) divide CPs into three types based on the amount of automated support provided by the CP system. A like-for-like replacement of paper-based procedures (PBPs) with CPs (i.e., essentially electronic copies of the PBPs) generally results in a Type $1 \mathrm{CP}$, in which the basic functionality and mode of operation is maintained across the two technologies. Type 2 and $3 \mathrm{CPs}$ add functionality that was not possible with PBPs. Type 2 CPs embed relevant plant indications directly into the $\mathrm{CP}$ system display or linked secondary display, thereby eliminating the need for operators to search for relevant plant readings on control boards. Type $3 \mathrm{CPs}$ embed soft controls in CPs, whereby the operator can control plant functions via software at a local workstation rather than manually control plant functions at the control room panels. Note that this distinction not only applies to upgrades of existing main control rooms but also to new plant designs, which may represent the implementation of newer technologies relative to the existing control rooms in the operating fleet of nuclear power plants.

Despite clear advantages for ease of use, there remain regulatory concerns over the implementation and use of CPs. CPs introduce a new technology into the control room, one that potentially interfaces with the plant computer. The opportunity for the $\mathrm{CP}$ hardware or software to fail introduces new failure modes in the control room that are not part of existing plant risk profiles. Moreover, the operator interface with $\mathrm{CPs}$ is different than the interaction with existing PBPs, and there is the opportunity for different types of human error in procedure use. Insights on the human factors issues associated with CPs have been captured (e.g., Le Blanc, Gertman, and Boring, 2011), but there has been no categorization of these insights in terms of human reliability.
A central goal for phasing in newer technologies is to ensure that a new system is at least as reliable as the system it is replacing. In terms of human reliability analysis (HRA), the goal is to ensure that operator performance using the newer technology is at least as reliable as performance using the older technology. Such a comparison may be made by estimating the human error probabilities (HEPs) of various human activities, including human failure events (HFEs).

The challenge of new technology is that it, in many cases, is newer than the tools used to evaluate it. Such is clearly the case with CPs and HRA. NUREG-1842, Evaluation of Human Reliability Analysis Methods Against Good Practices (Forester et al., 2006), outlines a variety of HRA methods. Commonly used HRA methods currently in use in the U.S. nuclear industry include THERP, ASEP, SPAR-H, and ATHEANA, HCR/ORE, CBDT, and the EPRI HRA Calculator (which is actually a collection of methods rather than a single method). It is important to note that none of these HRA methods was explicitly designed to deal with CPs. At the present time, these HRA methods do not provide supplemental guidance to explain how to use these methods to evaluate operator performance with digital systems, including CPs.

Outside the U.S., there have been two documented efforts to develop HRA methods that support CPs. The first, MERMOS (Méthode d'Evaluation de la Réalisation des Missions Opérateur pour la Sûreté; Le Bot, 2003), is a method developed by Electricité de France (EDF) to address HRA in support of the CPs used in the N4 class of reactors. Originally, EDF used ASEP to model operator performance on pre-initiator events and THERP on post-initiator events. However, it was determined that these approaches were very driven by a serial, procedural unfolding of events. The N4 $\mathrm{CP}$ system diagnosed situations dynamically, resulting in a less serial event progression. As such, the CPs may be viewed as state-based rather than the more traditional event based or symptom oriented procedures. In order to define HFEs that were more dynamic, the MERMOS approach was developed. The MERMOS method uses CICAs (Caractéristiques Importantes de la Conduite Accidentelle/ 
Key Characteristics for Accident Management)_rules that the operators and CPs follow and that can be reconfigured as required, such as when there is a change to plant state requiring a new response. The primary difference between MERMOS and other methods is its heavy emphasis on the dynamic response of the operator, which is triggered by the rapid reconfiguration of the $\mathrm{CPs}$ when the plant state changes. The second approach to HRA for CPs is still under development by the Korea Advanced Institute of Science and Technology (KAIST; Seung, Ha, and Seong, 2010) and does not yet provide a complete method for review. Since MERMOS is not currently used in the U.S. for nuclear licensing applications and since the KAIST method is still under development, it is important to review the current generation of U.S. HRA methods and consider their suitability for CPs.

CPs represent a combination of factors related to traditional PBPs as well as factors associated with advanced HSIs. CPs feature human error and success opportunities unique to CPs but also overlap to a certain degree with PBPs and with advanced human system interfaces (HSIs). For example, as with PBPs, it may still be possible to omit steps within CPs, but the likelihood is lower with most CP designs. CPs may feature additional checking of step completion, which has the potential to lower the frequency of skipped steps. However, the system is not without tradeoffs. Because in CPs the procedures are part of a software system, there is the opportunity for hardware or software failure, which represents a new failure mode not even possible in PBPs. Additionally, performance issues known to occur in advanced HSIs, such as loss of operator vigilance during automated actions, may also occur in Type 2 or 3 CPs.

In many ways, computerized procedures are a specialized case of advanced HSIs. As such, many of the system and human-system failure modes can be expected to be similar. That said, it is incumbent on the human reliability analysts reviewing scenarios involving operator interaction with CPs to include in their review the human performance features for the advanced control room environment of which the CPs are an integral part.

\section{HUMAN RELIABILITY ANALYSIS METHODS Coverage}

In an earlier paper, Boring, Gertman, and Le Blanc identified specific factors that HRA should consider (2011). In this paper, we extend this work by briefly reviewing HRA methods commonly used by EPRI and the U.S. NRC, and how these methods treat both paper-based and computerized procedures. The methods discussed include CBDT developed for EPRI and THERP, ASEP, SPAR-H, and ATHEANA developed for the U.S. NRC. Note that these methods closely overlap those methods covered in the EPRI HRA Calculator, with two exceptions:

- HCR/ORE, which is found in the EPRI HRA Calculator, is not included at any depth in this discussion because it is strictly used for time-reliability calculations. The extent to which time plays a differential role in the use of paper-based vs. computerized procedures is not currently known. To the extent time margins are known, this method may be applied with equal validity to either paper-based or computerized procedures.

- $\quad$ ATHEANA is discussed here, which is not found in the EPRI HRA Calculator. ATHEANA is a secondgeneration HRA method that does not feature a narrowly defined taxonomy and therefore provides flexibility suitable for addressing computerized procedures.

Currently, every HRA method in use in the U.S. predates the advent of computerized procedures. As such, the selection of a particular method must consider the suitability of that method to the particular computerized procedure issue under analysis. In addition, the analyst may wish to consult NUREG-1842, Evaluation of Human Reliability Analysis Methods Against Good Practices (Forester et al., 2006), which provides a comprehensive set of criteria that are useful in evaluating particular HRA methods outside the context of computerized procedures. In NUREG-1842, a general framework for evaluating and using a particular HRA method is provided. To augment the guidance in NUREG-1842 with respect to HRA for computerized procedures, two considerations are important:

- For a qualitative analysis, it is important that the method allows consideration for the types of HFEs and performance shaping factors (PSFs) that affect operator performance in using computerized procedures.

For quantitative analysis, it is important that the method adequately address insights specific to computerized procedures derived from the qualitative analysis.

\section{U.S. NRC Backed HRA Methods THERP}

Beginning with the earliest HRA method, the Technique for Human Error Rate Prediction (THERP; Swain and Guttman, 1983), HRA methods have to varying degrees addressed procedures. THERP uses procedures in the determination of the nominal HEP. For example, in the screening phase depicted in THERP Table 20-2, procedures are the primary determiner of the HEP. The "failure to perform rule-based actions correctly when written procedures are available and used" is given an HEP of 0.05 per critical step without recovery factors and 0.025 with recovery factors. However, if written procedures are not available or used, the screening HEP goes up to 1.0. In other words, in a conservative screening analysis using THERP, no credit is given for operator performance in rule-based actions by control room personnel after diagnosis of an abnormal event when procedures are unavailable or aren't used. Procedures also figure prominently in the detailed (non-screening) analysis of THERP. For example:

- Table 20-5, "Estimated HEP per item (or perceptual unit) in preparation of written material" - omitting a step from a procedure or writing an item incorrectly per 
a procedure, which is clarified to mean errors in the preparation of written procedures.

- Table 20-6, "Estimated HEP related to failure of administrative control"- - use of written procedures during normal vs. abnormal operating conditions or use of calibration and maintenance procedures.

- Table 20-7, "Estimated probabilities of errors of omission per item of instruction when use of written procedures is specified"- essentially the entire table is related to the use of written procedures.

THERP also considers procedures as a modifier (essentially, a PSF). For example, the differential effects of procedures on stress for skilled and novice operators are accounted for in THERP Table 20-16. Having routine, procedurally guided tasks results in lower overall multipliers applied to the nominal HEP than does performing tasks without procedures.

THERP is the predecessor of modern HRA methods. With a fifty-year history (Boring, these proceedings), THERP predates emerging control room technologies and digital systems. As discussed in Chapter 10 of NUREG/CR1278, THERP features explicit coverage of procedures, in part in response to the need to develop symptom-based procedures following the Three Mile Island incident in the U.S. (Kemeny et al., 1979). While THERP's treatment of procedures is adequate for paper-based procedures, there is no bridge within the documentation to newer technologies and, of course, no treatment of computerized procedures.

The most likely candidate tables in THERP for computerized procedure applications are:

- Table 20-7: Procedural Items-e.g., skipping a step in a procedure

- Table 20-9: Display Selection-e.g., selecting the wrong display to accompany a procedure or selecting the wrong procedure

- Table 20-12: Control Selection or Use-e.g., selecting the wrong control or selecting the wrong setting

Note that these tables were published in 1983 and should not be considered as reflecting state-of-the-art digital displays found in current or future plants. The HEPs provided with the tables have not been validated against modern control room technologies. Note also that these tables do not take into consideration PSFs like Communications or Situation Awareness, which can be significant contributors to human performance deficiencies in working with computerized procedures.

\section{ASEP}

The Accident Sequence Evaluation Program (ASEP) HRA method (NUREG/CR-4772: Swain, 1987) was developed as a simplification of THERP suitable for use in post-accident analyses performed at the U.S. NRC. The method includes screening and nominal HEPs for pre- and post-initiators (called pre- and post-accident tasks within the method). The values of these HEPs are meant to help analysts determine if an event is risk significant and to provide a first-order approximation of the HEP without a detailed THERP analysis. As a simplification of THERP, ASEP features many of the same limitations as are found in THERP.

ASEP provides the following coverage of written checklists, which are essentially procedures for maintenance tasks as pre-initiators. ASEP Tables 4-2 (Screening HEP) and 5-2(2) (Nominal HEP) provide, among other things, procedure considerations for basic plant conditions:

- Item 3: ...the verification does not require use of a written checkoff list.

- Item 4: Shiftly or daily checks of component status (in or outside of the control room) are done without using a written checkoff list, or are not done at all.

In contrast, ASEP Tables 4-3 (Screening HEP) and 5-2(3) (Nominal HEP) consider optimum plant conditions for pre initiators:

- Item 3: ... No credit is given for either check unless a written test is used during a test.

- Item 4: There is a requirement for a shiftly or daily check of component status (in or outside the control room), using a written list.

ASEP provides the following coverage of procedures for post-initiators in Tables 7-3 (Screening HEP) and 8-5 (Nominal HEP):

- Item 3: Perform a critical procedural action correctly under moderately high stress.

- Item 4: Perform a critical procedural action correctly under extremely high stress.

- Item 5: Perform a post-diagnosis immediate emergency action for the reactor vessel/containment critical parameters, when (a) it can be judged to have been committed to memory, (b) it can be classified as skillbased action per Table 2-1, and (c) there is a backup written procedure.

While these items account for the failure to use procedures correctly pre- and post-initiator, they do not adequately address procedure quality nor elements of the interface that might prove relevant to computerized procedure implementation. In addition, ASEP offers no treatment of PSFs and does not cover the PSFs relevant to computerized procedures

\section{SPAR-H}

The Standard Plant Analysis Risk-Human Reliability Analysis (SPAR-H; NUREG/CR-6883: Gertman et al., 2005) method was developed as a further simplification of THERP, specifically to address the need to develop HRAs to support the Standard Plant Analysis Risk (SPAR) generic PRA models used by the U.S. NRC. Whereas THERP and, to a lesser extent, ASEP were developed around a set of predefined task types to which analysis HFEs were mapped, SPAR-H provides only two categories of activitiesdiagnosis and action. These two activity types feature nominal HEPs, which are then modified by weights assigned to different levels of eight PSFs. An initial version of SPAR-H was released in 1994, with two subsequent refinements, culminating in NUREG/CR-6883 in 2005. The latest version of SPAR-H adds to earlier versions a new PSF 
for Ergonomics and Human-Machine Interfaces, thus allowing the method to encompass a variety of interface technologies.

Of its eight PSFs, SPAR-H features four PSFs that are particularly relevant to computerized procedures, as listed below:

- "Procedures" refers to the existence and use of formal operating procedures.

- "Ergonomics and Human-Machine Interface (HMI)" refer to displays and controls, layout, and quality of information available from the instrumentation and controls.

- "Complexity" refers to how difficult the task is to perform in a given context.

- "Work Processes" refer to aspects of doing work, including communication.

These PSFs give SPAR-H good coverage of the factors noted to influence operator performance in the use of computerized procedures. The multipliers for Procedures and Ergonomics/HMI can be as high as 50, meaning a nominal HEP of 1E-3 could increase to as high as 5E-2 for either PSF alone. In practice, assignment of the PSFs to levels with these high multipliers is extremely rare but serves to highlight the importance of these two PSFs as drivers on operator performance.

The use of PSFs in SPAR-H affords the method considerable generalizability beyond that found with task types in THERP and ASEP. Despite this generalizability, the basis for quantification of these PSFs is grounded in THERP (Boring and Blackman, 2007), and caution should be exercised before generalizing too broadly. As with THERP, quantification in SPAR-H has not been validated against newer technology applications.

\section{ATHEANA}

Second-generation HRA methods like A Technique for Human Error Analysis (ATHEANA; Forester et al., 2007; U.S. Nuclear Regulatory Commission, 2000) were developed out of a need to accommodate event scenarios and activity types that were not readily accounted for with methods like THERP. Thus, early work on ATHEANA featured a significant emphasis on low power and shutdown applications. Additional analyses showed the flexibility of the method to be used in analyses for unusual yet plausible events. The ATHEANA method includes a search strategy to help analysts identify contexts in which operators might deviate from the expected path. ATHEANA does not include a formal list of activity types nor PSFs, and it uses expert estimation to generate HEPs. In practice, this approach has required considerable expertise and may be subject to greater inter-analyst variability than firstgeneration HRA methods like THERP (Forester et al., 2006). Nonetheless, the considerable flexibility of ATHEANA makes it an ideal candidate for use in new technology domains like computerized procedures. Given the considerable expertise required for an ATHEANA analysis, the application of the method to computerized procedures should not be undertaken casually, and additional guidance will be required for its use. For example, ATHEANA was recently adapted for use in scoping analyses for fire HRA events (U.S. Nuclear Regulatory Commission, 2009). Such explicit guidance helps to guide the ATHEANA analyst in a reasonable analysis process for fire applications, but comparable guidance does not currently exist for the application of ATHEANA to computerized procedures.

Although ATHEANA is an open method, it features guidance for existing applications, including procedure following. Section 9.5.4 in NUREG-1624, Rev. 1, offers guidance for evaluation of formal rules and emergency operating procedures. Of particular value is a series of tables explicating areas in emergency operating procedures that may be error prone in certain contexts. To the extent that computerized procedures follow the same procedure logic and content found in existing paper-based procedures, these tables are invaluable in aiding the analyst in considering the operators' potential problem areas in procedure following. Further, although ATHEANA does not offer a formal or prescribed list of PSFs, there is detailed discussion of a number of common PSFs, including "Suitability of Relevant Procedures and Administrative Controls."

\section{EPRI Backed HRA Methods HCR/ORE}

As noted in the introduction section, Human Cognitive Reliability/Operator Reliability Experiments (HCR/ORE; EPRI TR-100259, 1992) is a time-reliability method. There is anecdotal evidence to suggest that computerized procedures may decrease the time for operators to perform tasks. There is, however, no technical basis for assuming that time will be a significant factor in computerized procedure use nor that it will have a different impact of the HRA compared with a similar analysis for paper-based procedures. As such, HCR/ORE is judged not to cover unique factors for computerized procedures.

\section{CBDT}

EPRI's Cause-Based Decision Tree (CBDT; EPRI TR100259, 1992) method was released in 1992 as a simplified framework for quantifying the cognitive or diagnostic portion of an HFE. The method was developed as a complement to $\mathrm{HCR} / \mathrm{ORE}$, specifically to handle situations where time is not a limiting factor. CBDT looks at two highlevel failure modes:

- Operator-information interface failure, and

- Operator-procedure interface failure.

Each of these failure modes has four failure mechanisms, represented by a binary decision tree with three or four corresponding branching points. Thus, in total, the method has eight decision trees that the analyst considers independently to arrive at the failure paths. The nomenclature for each tree is $p_{c}$ (short for cause path), with a further letter designator, $a-g$, to designate each tree.

Because CBDT considers elements of the HSI and procedures in the two failure modes, CBDT is ideally suited 
for addressing most issues pertaining to procedure use. However, the delineation of the HSI and procedures precludes an important area for CPs - the overlap of the HSI with procedures. Certain phenomena-notably CP issues identified by Seung et al. (2010) are not easy to map to the decision trees found in CBDT. The extent to which these issues may be subsumed by existing failures identified in CBDT remains open.

\section{DISCUSSION}

While no method adequately envelops all considerations necessary for computerized procedures, these methods offer a good starting point to the analyst. For example, the SPAR$\mathrm{H}$ method provides a list of PSFs that are well-suited for computerized procedures; CBDT offers a series of decision trees for HSI and procedures that bridges many of the factors relevant for computerized procedures; ATHEANA offers extensive guidance on errors in using paper-based procedures while being extensible to computerized procedures.

The use of any single HRA method for computerized procedures represents a tradeoff. The suitability of a particular method to evaluating computerized procedure use is dependent on the specific features of the computerized procedures that are likely to influence operator performance and on the ability of the analyst to extrapolate the method to the domain of computerized procedures. Care should be taken not to overgeneralize the method nor to overlook unique characteristics of computerized procedures that are not adequately addressed in current methods.

\section{DISCLAIMER}

This work of authorship was prepared as an account of work sponsored by an agency of the United States Government. Neither the United States Government, nor any agency thereof, nor any of their employees makes any warranty, express or implied, or assumes any legal liability or responsibility for the accuracy, completeness, or usefulness of any information, apparatus, product, or process disclosed, or represents that its use would not infringe privately-owned rights. Idaho National Laboratory is a multiprogram laboratory operated by Battelle Energy Alliance LLC, for the United States Department of Energy under Contract DE-AC07-05ID14517.

\section{REFERENCES}

Boring, R.L. (2012). Fifty Years of THERP. Proceedings of the Probabilistic Safety Assessment and Management and European Safety and Reliability Conference (PSAM 11 \& ESREL 2012). In press.

Boring, R.L., \& Blackman, H.S. (2007). The origins of the SPAR-H method's performance shaping factor multipliers. Official Proceedings of the Joint 8th IEEE Conference on Human Factors and Power Plants and the 13th Annual Workshop on Human Performance/Root Cause/Trending/Operating Experience/Self Assessment, 177-184.

Boring, R. L., Gertman, D. I., \& Le Blanc, K. (2011). Human reliability analysis for computerized procedures. Proceedings of the Human Factors and Ergonomics Society 55th Annual Meeting, 1720-1724.
EPRI. (1992). An Approach to the Analysis of Operator Actions in Probabilistic Risk Assessment, TR-100259. Palo Alto: Electric Power Research Institute.

EPRI. (2010). Computerized Procedure Systems: Guidance on Design, Implementation and Use of Computerized Procedure Systems, Associated Automation and Soft Controls,TR-1015313. Palo Alto: Electric Power Research Institute.

Fink, R., Killian, C., Hanes, L., \& Naser, J. (2009). Guidelines for the design and implementation of computerized procedures. Nuclear News. VOL 52 (3), 85-88, 90.

Forester, J., Kolaczkowski, A., Cooper, S., Bley, D., \& Lois, E. (2007). ATHEANA User's Guide, NUREG-1880. Washington, DC: US Nuclear Regulatory Commission.

Forester, J., Kolaczkowski, A., Lois, E., \& Kelly, D. (2006). Evaluation of Human Reliability Analysis Methods Against Good Practices, Final Report, NUREG-1842. Washington, DC: US Nuclear Regulatory Commission.

Gertman, D., Blackman, H., Marble, J., Byers, J., \& Smith, C. (2005). The SPAR-H Human Reliability Analysis Method, NUREG/CR-6883. Washington, DC: US Nuclear Regulatory Commission.

International ElectroTechnical Commission 62646. (2010). Nuclear Power Plants Control Rooms Computer Based Procedures, the IEC National Committee, in Compliance with the ISO/ISO directives, Geneva, Switzerland

IEEE (2009). Human Factors Guide for Applications of Computerized Operating Procedure Systems at Nuclear Power Generating Stations and other Nuclear Facilities (Draft Guideline 1786, 9/30/09 version). New York, NY: Institute of Electrical and Electronics Engineers.

Kemeny, J.G., et al. (1979). Report of the President's Commission on The Accident at Three Mile Island. Washington, DC: The President's Commission on the Accident at TMI.

Le Blanc, K., Gertman, D., Boring, R., Hugo, J., and Xing, J. (2011). Human Factors Guidance for the Assessment of Computerized Procedures, INL/EXT-10-19155. Idaho Falls: Idaho National Laboratory.

Le Bot, P. (2003). Methodological validation of MERMOS by 160 analyses. In: Proceedings of the International workshop building the new HRA: errors of commission from research to application. NEA/ CSNI/R(2002)3. OECD: Issy-les-Moulineaux.

Seung, W.L., Ha, J.S., \& Seong, P.H. (2010). Development of an HRA Method based on Human Factor Issues for Advanced NPP. In Proceedings of the Seventh American Nuclear Society International Topical Meeting on Nuclear Plant Instrumentation, Control and Human-Machine Interface Technologies NPIC\&HMIT 2010, Las Vegas, Nevada.

Swain, A.D. (1987). Accident Sequence Evaluation Program Human Reliability Analysis Procedure, NUREG/CR-4772. Washington, DC: US Nuclear Regulatory Commission.

Swain, A.D., \& Guttman, H.E. (1983). Handbook of Human Reliability Analysis with Emphasis on Nuclear Power Plant Applications, NUREG/CR-1278. Washington, DC: US Nuclear Regulatory Commission.

Swain, A.D. (1992). Human Reliability Analysis-Course Documentation. Knoxville, TN: Process Safety Institute/JBF Associates, Inc.

US Nuclear Regulatory Commission. (2000). Technical Basis and Implementation Guidelines for A Technique for Human Event Analysis (ATHEANA), NUREG-1624, Rev. 1. Washington, DC: US Nuclear Regulatory Commission.

US Nuclear Regulatory Commission/Electrical Power Research Institute. (2009). EPRI/NRC-RES Fire Human Reliability Analysis Guidelines, Draft Report, NUREG-1921. Washington, DC: US Nuclear Regulatory Commission. 